\title{
Spraying Respiratory Epithelial Cells to Coat Tissue-Engineered Constructs
}

\author{
Anja Lena Thiebes, ${ }^{1}$ Stefanie Albers, ${ }^{1}$ Christian Klopsch, ${ }^{2}$ Stefan Jockenhoevel, ${ }^{1,3}$ and Christian G. Cornelissen ${ }^{1,4}$
}

\begin{abstract}
Applying cells in a spray can overcome current hurdles in coating tissue engineered constructs with a thin layer of endo- or epithelial cells. We report here a structured study on the influences of spray application with a medical spray device on vascular smooth muscle cells (VSMCs) and respiratory epithelial cells (RECs) with and without fibrin gel. Next to viability and cytotoxicity assays, the in vitro differentiation capacity after spray processing was analyzed. For VSMC, no influence of air pressures till 0.8 bar could be shown, whereas the viability decreased for higher pressures. The viability of RECs was reduced to $88.5 \%$ with 0.4 bar air pressure. Lactate dehydrogenaselevels in the culture medium increased the first day after spraying but normalized afterward. In the short term, no differences by means of morphology and expression-specific markers for VSMCs and RECs were seen between the control and study group. In addition, in a long-term study for 28 days with the air-liquid interface, RECs differentiated and built up an organized epithelial layer with ciliary development that was comparable to the control for cells sprayed without fibrin gel. When spraying within fibrin gel, ciliary development was lower at 28 days. Thus, spraying of vSMCs and RECs was proved to be a suitable method for tissue engineering. Especially for RECs, this application is of special significance when coating luminal structures or other unfavorable topographies.
\end{abstract}

Key words: aerosolization; cell seeding; cell transfer; respiratory epithelium; tissue engineering; viability

\section{Introduction}

The technique of spraying cells was proposed by Bahoric et al. with an in vitro study in which epidermal cells were sprayed on cell culture plates with a pumpaction aerosol nozzle. ${ }^{1}$ Since then, researchers have accomplished both in vivo and in vitro studies with different experimental setups and techniques. Various types of spraying devices were used: commercially available airbrush pistols, ${ }^{2-4}$ pump heads, ${ }^{1,5}$ atomizers, ${ }^{6}$ and clinically used spray nozzles. ${ }^{7-9}$ However, systematic studies on the influence of spray processing on different cell types are still sparse. Especially for the field of tissue engineering, spraying is a highly promising option: As necessary for epithelial or endothelial cells, thin (single) cell layers can be applied onto tissue-engineered constructs.
In vitro studies have revealed diverse results on cell behavior and survival after spraying depending on procedure and cell type. When analyzing the influence of nozzle diameters and air pressures on fibroblast survival, decreasing viability with increasing pressures and decreasing airbrush nozzle diameter with viabilities ranging between $37 \%$ and $94 \%$ was found. ${ }^{4}$ As described by Duncan et al., different hydrostatic, shear, and elongation stresses act on the cells and might be a reason for this variance. ${ }^{10}$

Looking at in vivo experiments and clinical studies, different models were investigated. So far, the main focus was on wound healing for burn or chronic wounds, ${ }^{5,7,11-13}$ Better epithelial coverage and histological results in a porcine wound closure model have been

\footnotetext{
${ }^{1}$ Department of Tissue Engineering and Textile Implants, Institute of Applied Medical Engineering, Helmholtz Institute, RWTH Aachen University, Aachen, Germany. ${ }^{2}$ Clinic and Policlinic for Cardiac Surgery, University of Rostock, Rostock, Germany.

${ }^{3}$ Aachen-Maastricht Institute for Biobased Materials, Maastricht University at Chemelot Campus, Geleen, The Netherlands.

${ }^{4}$ Section for Pneumology, Department for Internal Medicine, Medical Faculty, RWTH Aachen University, Aachen, Germany.

*Address correspondence to: Univ.-Prof. Dr. Med. Stefan Jockenhoevel, Department of Tissue Engineering and Textile Implants, Institute of Applied Medical Engineering, Helmholtz Institute, RWTH Aachen University, Pauwelsstraße 20, Aachen 52074, Germany, E-mail: jockenhoevel@ame.rwth-aachen.de
}

(C) Anja Lena Thiebes et al. 2015; Published by Mary Ann Liebert, Inc. This Open Access article is distributed under the terms of the Creative Commons License (http://creativecommons.org/licenses/by/4.0), which permits unrestricted use, distribution, and reproduction in any medium, provided the original work is properly credited. 
shown when spraying epithelial cells. ${ }^{11}$ Similar results have been obtained by Goedkoop et al., who have clinically tested the effect of keratinocytes and fibroblasts delivered in a fibrin matrix on closure of chronic leg ulcers. ${ }^{5}$

Fibrin has been frequently used when spraying cells onto different surfaces ${ }^{7-9,13-15}$ : Hafez et al. proved the positive impact of spraying a mixture of smooth muscle cells and urothelial cells with fibrin gel on decellularized colonic segments for bladder augmentation in piglets. ${ }^{12}$ Fibrin is clinically used as tissue glue in plastic surgery and also applied for various tissue engineering applications, as it can be isolated autologously. ${ }^{16,17}$ For spraying of cells, fibrin has the advantage that it polymerizes fast to keep the cells in place but degradation takes place within a few days, which then allows (epithelial) cells to differentiate in situ. Fibrin gel is, hence, a very suitable material for this approach.

Although only little research on cell spraying has been carried out for tissue engineering of the respiratory tract, we propose that it is a viable option to seed epithelial cells on the luminal surface of tissueengineered tubular constructs. So far, only one study analyzed growth kinetics of tracheal epithelial cell when sprayed with an atomizer on microscope slides and no significant differences to pipetted controls were found. $^{6}$

In our lab, endothelial cells are successfully coated on a viable tissue-engineered construct based on a fibrin gel scaffold as shown by Weinandy et al. with the BioStent concept. ${ }^{18}$ The same approach with respiratory epithelial cells (RECs) was not successful (upublished data). However, the suitability of fibrin gel for culture and differentiation of RECs was already shown in our lab. ${ }^{19}$

Thus, to directly apply the cells where desired, spraying is highly interesting. The main objectives for this study are to assess the general suitability of a commercially available spray device (Tisseel, EASYSPRAY set; Baxter) and to find the best spraying conditions as determined by ovine vascular smooth muscle cell (vSMC) and REC survival, proliferation, and lysis. Furthermore, differentiation of both cell types will be proved, especially the long-term differentiation of the RECs with ciliary development after spraying with and without fibrin gel.

\section{Materials and Methods}

Cell culture

Ovine carotid arteries (with a length of $10 \mathrm{~cm}$ ) and tracheas (with a length of $5-7 \mathrm{~cm}$ ) were harvested from sheep euthanized for other purposes at the Institute of Laboratory Animal Science in the University Hospital Aachen under sterile conditions and immediately placed in transport buffer (100 mM HEPES, $140 \mathrm{mM}$ $\mathrm{NaCl}$ [Sigma-Aldrich ${ }^{\circledR}$ ], $2.5 \mathrm{mM} \mathrm{KCl}, 10 \mathrm{mM}$ glucose [both Merck], 1\% antibiotic-antimycotic solution $\left[\mathrm{ABM} ; \mathrm{Gibco}^{\circledR}\right] ; \mathrm{pH}$ 7.4). The procedures used conformed to the "Guide for the care and use of laboratory animals" published by the US National Institutes of Health (The National Academies Press, 2011).

A mixed population of smooth muscle cells/ fibroblasts (vSMC) was harvested by outgrowth from ovine carotid artery rings in Dulbecco's modified essential medium (DMEM; Gibco) supplemented with $10 \%$ fetal bovine serum (Gibco) and 1\% ABM as described by Tschoeke et al. ${ }^{20}$ RECs were isolated according to a protocol first published by Yamaya et al. ${ }^{21}$ : The mucosa was incised longitudinally; mucosa strips were removed, placed in a solution of $1.8 \mathrm{U} / \mathrm{mL}$ protease XIV (Sigma-Aldrich), and incubated at $4^{\circ} \mathrm{C}$ overnight. After removal of the strips and centrifugation, the cells $\left(\sim 5 \times 10^{5}\right)$ were dispersed in DMEM, seeded in cell culture flasks, and maintained in a humidified incubator at $37^{\circ} \mathrm{C}$ and $5 \% \mathrm{CO}_{2}$. After $24 \mathrm{~h}$, the medium was changed to Airway Epithelial Cell Growth Medium (PromoCell). When cells reached $70-80 \%$ of confluence, cells were detached using $0.05 \%$ trypsin $/ 0.02 \%$ EDTA solution (PAN-Biotech). RECs in passage 1 (after 2 weeks of culture) and vSMCs till passage 5 ( $\sim 6-8$ weeks in culture) were used for this study.

\section{Spraying experiments}

For an overview of all experiments, please see Table 1. The spraying setup is shown in Figure 1. All cell experiments were accomplished under sterile conditions. For the spraying experiments, Tisseel EASYSPRAY Sets ${ }^{\mathrm{TM}}$ (Baxter) were used with two $1 \mathrm{~mL}$ syringes (BD Plastipak $\left.^{\mathrm{TM}}\right)$. For experiments with fibrin gel, commercial fibrinogen $\left(20 \mathrm{mg} / \mathrm{mL}\right.$; Calbiochem $\left.{ }^{\circledR}\right)$ and polymerization

\section{Table 1. Overview of Experiments Conducted in This Study} for the Respective Cell Type

\begin{tabular}{|c|c|}
\hline Vascular smooth muscle cells & Respiratory epithelial cells \\
\hline $\begin{array}{l}\text { Viability for different pressures } \\
\quad(0,0.4,0.8,1.2,1.6,2 \text { bar })\end{array}$ & Viability (0.4 bar) \\
\hline $\begin{array}{l}\text { Viability for different velocities } \\
\quad(10,30,55,75,95 \mathrm{~mL} / \mathrm{min})\end{array}$ & $\begin{array}{l}\text { Short-term differentiation } \\
\text { (pan-cytokeratin expression) }\end{array}$ \\
\hline $\begin{array}{l}\text { Short-term differentiation } \\
\text { ( } \alpha \text {-SMA expression) }\end{array}$ & $\begin{array}{l}\text { Long-term differentiation } \\
\text { (14 and } 28 \text { days: pan-cytokeratin } \\
\text { expression and PAS reaction) }\end{array}$ \\
\hline
\end{tabular}




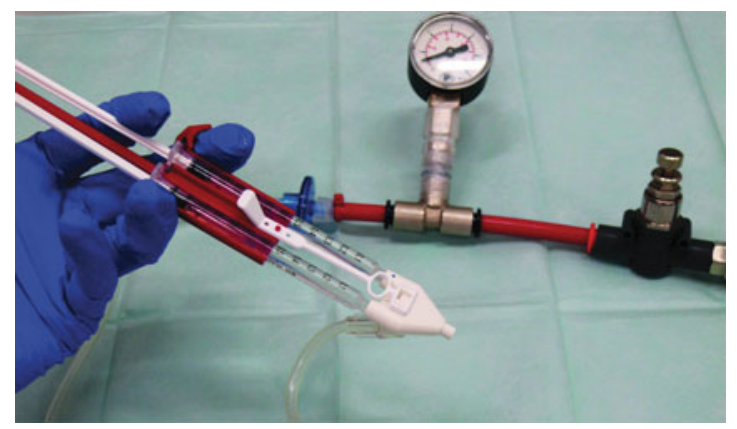

FIG. 1. Spray setup with pressure regulator and -gauge (at the top), spraying nozzle (front), and syringe holder with syringes (left).

solution (Tris-buffered $\mathrm{CaCl}_{2}[7.5 \mathrm{mM}]$ and $6 \mathrm{IU} / \mathrm{mL}$ thrombin) were prepared as previously described and cells were resuspended in the polymerization solution. ${ }^{22}$ Fibrinogen and polymerization solution were drawn into separate syringes. For all other experiments, the cell suspension was applied with both syringes simultaneously. Distance to the substrate was $2 \mathrm{~cm}$. Air pressure was adjusted to values between 0.4 and 2 bar with a pressure gauge. In the first experiment, the pressure was varied to analyze its influence on vSMC survival; cell suspension was injected by hand with a flow rate of $7-10 \mathrm{~mL} / \mathrm{min}$. For all following experiments, the pressure was set to 0.4 bar. In the second experiment, the cell suspension was injected with a syringe pump (Perfusor ${ }^{\circledR}$ Compact; B. Braun) with the indicated flow velocities of 10,30 , 55,75 , and $95 \mathrm{~mL} / \mathrm{min}$. Further, the suspension was injected by hand as fast as possible $(120-150 \mathrm{~mL} / \mathrm{min})$, named "manual" in the diagram.

For all short-term experiments, a $200 \mu \mathrm{L}$ cell suspension was added to wells of a 12 -well plate (CellStar ${ }^{\circledR}$; Greiner Bio-One) with a density of $5 \times 10^{4}$ and $8 \times 10^{4}$ cells $/ \mathrm{cm}^{2}$ for vSMCs and RECs, respectively. As a positive control, the same setup was used without air flow. For all statistically analyzed experiments, the number of samples was 5; from each sample, five images were taken at distinct areas of the well. For the cell survival and differentiation studies, cells were resuspended in Dulbecco's phosphate-buffered saline (PBS; Gibco) or in the respective culture medium. For differentiation analysis, cells were cultured for 3-5 days until confluency and then fixed and stained as described next. Visual inspection of cell morphology and medium change were done daily.
For long-term culture of RECs, the cells were directly sprayed into Transwell ${ }^{\circledR}$ inserts (Corning) in a 12 wellplate with the same density as described earlier with $n=3$. The insert membrane was precoated with collagen (from human placenta, Bornstein and Traub Type IV, $0.7 \mu \mathrm{g} / \mathrm{cm}^{2}$; Sigma-Aldrich). Transepithelial electrical resistance was measured (see Fig. 2 for representative curve). After 7 days of culture, air-liquid interface culture was established and a modified Airway Epithelial Cell Growth Medium with retinoic acid was used ( $50 \mathrm{nM}$, Sigma-Aldrich; protocol from PromoCell). The medium was changed every other day.

\section{Live-dead staining}

For cell survival studies, live-dead staining was conducted with calcein AM (AAT Bioquest ${ }^{\circledR}$ ) and propidium iodide (PI; Sigma-Aldrich). First, cells were detached from the cell culture flasks, counted with $\mathrm{CASY}^{\circledR}$ cell counter (Schärfe Systems), and resuspended in PBS or medium. Then, living cells were stained with calcein AM $(4 \mu \mathrm{M})$ for $30-60 \mathrm{~min}$ at $37^{\circ} \mathrm{C}$. After performing the spraying experiment, PI $(1 \mu \mathrm{g} / \mathrm{mL})$ was added to stain dead cells. Images were acquired directly with a fluorescence microscope (Observer Z1 and Axio Imager; Carl Zeiss) and a high-resolution CCD camera (AxioCam MRC; Carl Zeiss).

\section{Image processing}

For automated analysis, the images were processed with a self-written macro for counting particles in ImageJ (Version 1.44p). All images were processed with the same parameters to ensure comparability.

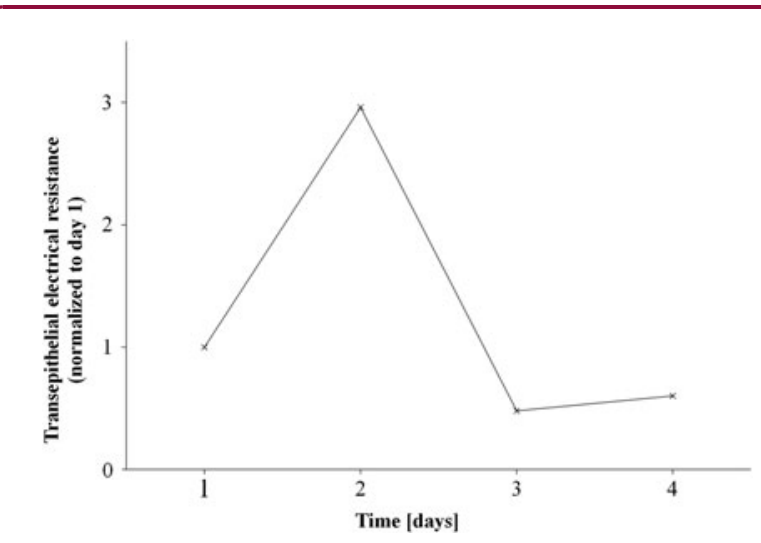

FIG. 2. Representative transepithelial electrical resistance (TEER) curve of sprayed cells in inserts for days $1-4$. 


\section{XTT assay}

To analyze whether spraying influences the proliferation, an XTT assay (Roche Diagnostics) with $n=5$ was accomplished. Cells were sprayed in a 6-well plate (CellStar; Greiner Bio-One), and the suspension was then transferred into a 96-well plate (CellStar; Greiner Bio-One) for measuring. As a positive control, nonsprayed cells were pipetted into the wells; as a negative control, we used DMEM without fetal calf serum supplementation. On day 1, 3, and 6 after seeding, an XTT-reagent/coupling solution mixture (50:1) was added to each well; absorption was measured at $475 \mathrm{~nm}$ after $1 \mathrm{~h}$ of incubation at $37^{\circ} \mathrm{C}$.

\section{Lactate dehydrogenase measurements}

For measuring the lactate dehydrogenase (LDH) level in the cell culture medium, cells were sprayed or pipetted in a 24-well plate at the density noted earlier. On day 1, 3, and 6 , the medium was changed and LDH level was determined by our laboratory service. As a positive control, the well plate was put in $\mathrm{a}-80^{\circ} \mathrm{C}$ freezer for $30 \mathrm{~min}$.

\section{Histology and immunohistochemistry}

The cells of the short-term experiment were fixed in the well plates with $4 \%$ formalin in PBS for 5 min and then rinsed with PBS. Nonspecific blocking and permeabilization was conducted by incubation with $5 \%$ normal goat serum (NGS; Dako) in 0.01\% triton (SigmaAldrich) for $30 \mathrm{~min}$. Primary antibodies were incubated for $1 \mathrm{~h}$ at $37^{\circ} \mathrm{C}$. After rinsing the wells with PBS, the secondary antibodies were incubated for $30 \mathrm{~min}$ at $37^{\circ} \mathrm{C}$. The cells were rinsed with PBS and counterstained with DAPI (Carl Roth ${ }^{\circledR}$ ) for 5 min. After three washing steps, the plate was viewed with the fluorescence microscope and images were acquired with a high-resolution CCD camera.

For vSMCs, the first antibody was anti- $\alpha$-smooth muscle actin (species: mouse; Sigma-Aldrich) with a concentration of $1: 1000$ in 5\% NGS in $0.01 \%$ triton. As a secondary antibody, Alexa Fluor-594 (goat antimouse IgG; Life Technologies) was used with a concentration of 1:400. For RECs, as a first antibody we used anti-pan-cytokeratin (species: rabbit; Acris) with a concentration of 1:100. As a secondary antibody, Alexa Fluor-488 (goat anti-rabbit IgG; Life Technologies) was used with a concentration of 1:400. As a negative control, only the secondary antibody was used; exposure time was determined as the time that does not show any staining in the negative control. Preparation for histology, periodic acid Schiff's reaction (PAS), and pan-cytokeratin staining of paraffin sections was conducted as described earlier by Cornelissen et al. ${ }^{19}$

\section{Statistical analysis}

Mean values and standard deviations were calculated for each parameter. Finally, statistical significance between controls and study groups was tested with an unpaired, two-tailed Student's $t$-test in Microsoft Office Professional Plus 2010 Excel Version 14. A p-value below 0.05 was considered significant.

\section{Results}

Cell survival depending on air pressure and cell suspension velocity

To assess general suitability of the cell spraying process with the Tisseel EASYSPRAY set and to find the best parameters for the process, a first set of experiments was conducted with vSMCs. We tested the influence of air pressure and cell suspension velocity on cell survival directly after spraying with a calcein AM/ PI-staining. As shown in Figure 3A, six different air pressures between 0 (as a control) and 2 bar were tested. For pressures of 0.4 and 0.8 bar, cell survival was $100.7 \%$ and $99.2 \%$ as high as the control. From a pressure of 1.2 bar, the survival decreased significantly: Cell survival was $87.9 \%, 63.7 \%$, and $57.9 \%$ of the control for $1.2,1.6$, and 2 bar, respectively. Thus, spray pressure was adjusted to 0.4 bar for all the next experiments.

As another important parameter, we have tested the influence of the cell suspension velocity on cell survival. Other than the air pressure, the cell suspension velocity did not have an influence on cell survival. Values varied between $94.6 \%$ and $98.5 \%$ without any statistically significant difference (Fig. 3B). For further spraying experiments, cell suspension was injected slowly by hand ( $\sim-10 \mathrm{~mL} / \mathrm{min})$.

As RECs are, in general, more sensitive than vSMCs and isolation and culture is complex, we have tested the influence of the parameters determined earlier on the survival. In contrast to vSMCs, the survival decreased significantly: The survival rate of RECs when spraying with 0.4 bar was $88.5 \%$. The survival rate might be simply compensated by increasing the amount of the cells in the suspension by $13 \%$.

\section{$\mathrm{XTT}$ and LDH}

As shown in Figure 2C, there is no significant difference between sprayed cells and control by means of mitochondrial activity on days 1, 3, and 6 after the 

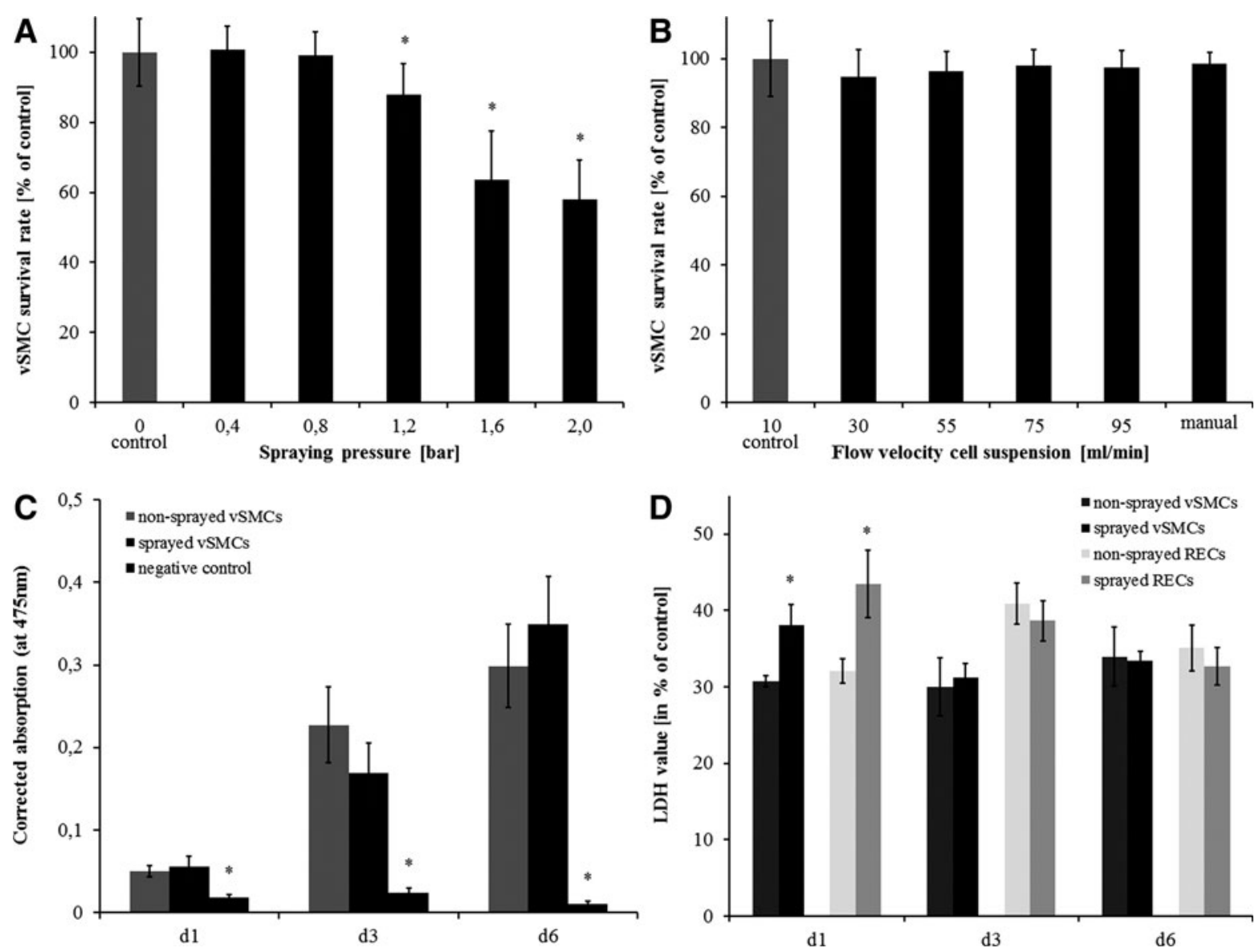

FIG. 3. Influence of spraying on cells. (A, B) vSMC survival depending on spray parameters assessed directly after spraying with calcein AM/propidium iodide staining. (A) VSMC survival depending on spray pressures between 0 and 2 bar; cell survival is comparable to the control till a pressure of 0.8 bar. (B) vSMC survival depending on cell suspension velocities; there is no influence on cell survival by flow velocities. (C) XTT assay with vSMCs: There is no significant difference in proliferation after 1, 3, and 6 days. (D) LDH levels of the sprayed cells compared with nonsprayed controls in \% of the positive controls. The LDH level of sprayed cells is significantly increased on day 1, but already normalized on day 3 (error bars indicate standard deviation, ${ }^{*} p<0.05$ to control). LDH, lactate dehydrogenase; vSMC, vascular smooth muscle cell.

experiment. Thus, spraying does not significantly influence the proliferation of vSMCs.

To assess the influence of the spray process on apoptosis or necrosis, the level of the intracellular enzyme $\mathrm{LDH}$ in the cell culture medium was examined on days 1,3 , and 6 after spraying for vSMC and RECs (Fig. 3D). On day $1, \mathrm{LDH}$ level was significantly increased in the sprayed samples for both cell types. On days 3 and 6, no increased LDH level could be detected and there was no significant difference between sprayed samples and controls anymore.

\section{Differentiation of vSMCs and RECs}

For proving cell differentiation potential in the short term after spraying, an immunohistochemical staining was conducted with antibodies against $\alpha$-smooth muscle actin ( $\alpha$-SMA) and pan-cytokeratin for vSMCs and RECs, respectively. The results are shown in Figure 4. In the upper row (Fig. 4A, B), images for vSMCs are depicted. When comparing the nonsprayed and sprayed cells, there is no difference in staining or intensity according to visual judgment of the microscopic images. All cells are stained with $\alpha$-SMA. Similar results 

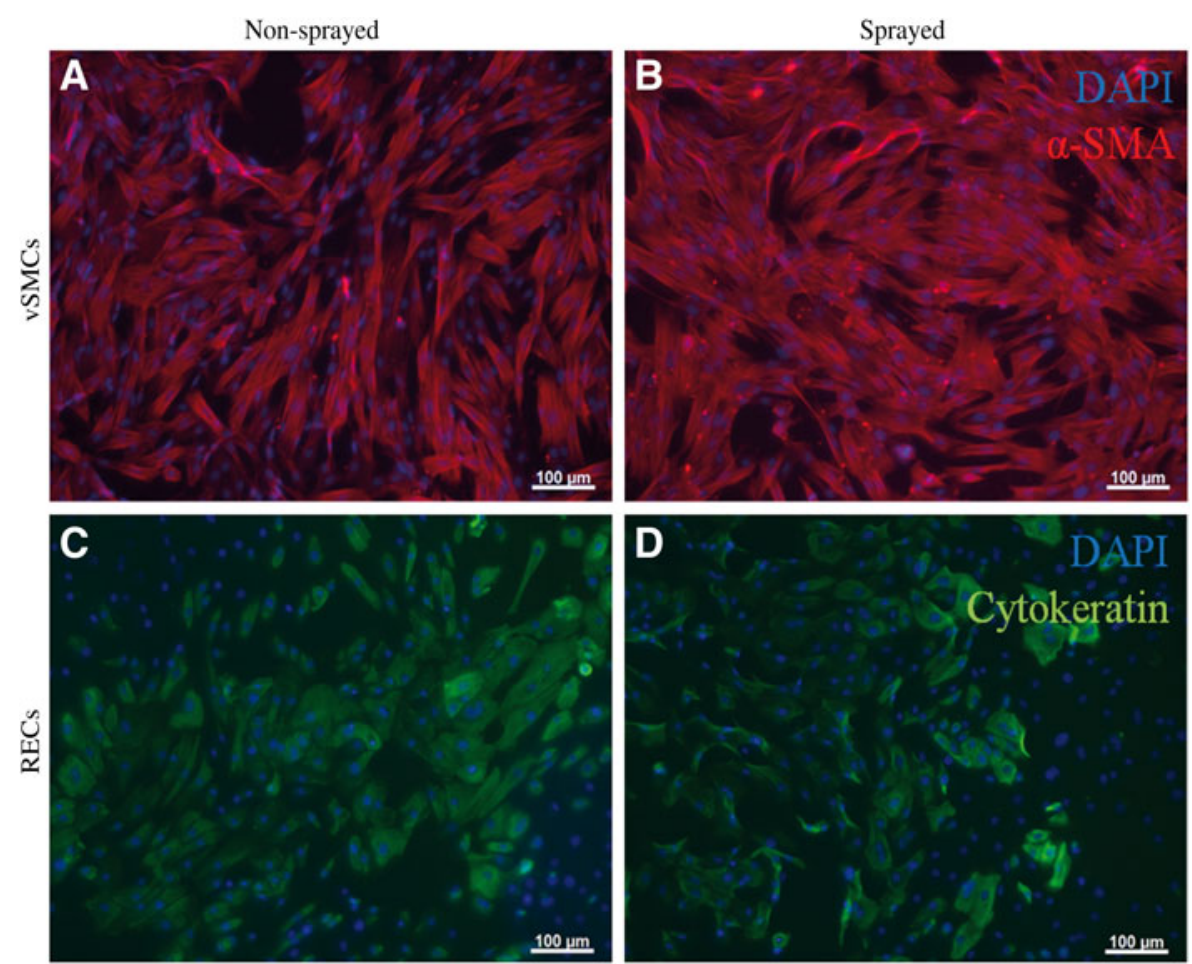

FIG. 4. Ability of vSMCs (A, B) and RECs to differentiate (C, D) after spray processing with 0.4 bar. (A, B) vSMCs were stained with $\alpha$-SMA antibody after 5 days of culture. Expression of $\alpha$-SMA is similar in control and sprayed cells. (C, D) RECs were stained with pan-cytokeratin antibody after 3 days of culture. Expression of cytokeratins is similar in control and sprayed cells. Scale bars: $100 \mu \mathrm{m}$. $\alpha$-SMA, $\alpha$-smooth muscle actin; RECs, respiratory epithelial cells.

are given for RECs in Figure 4C and D. Here, the majority of the cells are stained in both assays.

\section{Long-term culture of RECs without} and with fibrin gel

As RECs are a very sensitive cell type and dedifferentiate quickly in vitro, we have tested differentiation and ciliary development in long-term culture after spraying. Here, an experimental group was added, in which the cells were sprayed within a fibrin gel, as this is particularly interesting for tissue engineering approaches. Embedding the cells in fibrin gel will help the cells stay in place when applied onto uneven surfaces or on the inside of tubular constructs.

The results are shown in Figures 5 and 6. Histological images stained with PAS are shown for nonsprayed cells (Fig. 5A, B), sprayed cells (Fig. 5C, D), sprayed cells within fibrin gel (Fig. 5E, F), and native ovine trachea (Fig. 5G). After 14 days, RECs have built up a confluent epithelial layer with a pseudostratified appearance. In all assays, there is a layer of basal cells that have a smaller nucleus-to-cytosol ratio. After 28 days, in the sprayed and nonsprayed assay, the apical cells build up a mostly ciliated surface that is comparable to the native tracheal epithelium (Fig. 5, arrows). At that time point, there are also goblet cells in all samples (Fig. 5, arrowheads). However, these are not as distinct as in the native tissue. When spraying cells in fibrin gel, the ciliary development is not as advanced as in the other assays.

The immunohistochemical staining against pancytokeratin (Fig. 6) demonstrates a strong staining for all epithelial cells of the cultured constructs after 14 days. Thus, no dedifferentiation has taken place. In all experimental samples, the expression of cytokeratins is more uniform than in the native tissue. After 28 days, basal cells show a stronger staining than apical ones that is comparable to the expression pattern of the native tissue.

Thus, we show here that spraying of RECs without and with fibrin gel with an air pressure of 0.4 bar does not alter cell morphology, differentiation, ciliary development, and pan-cytokeratin expression pattern. 


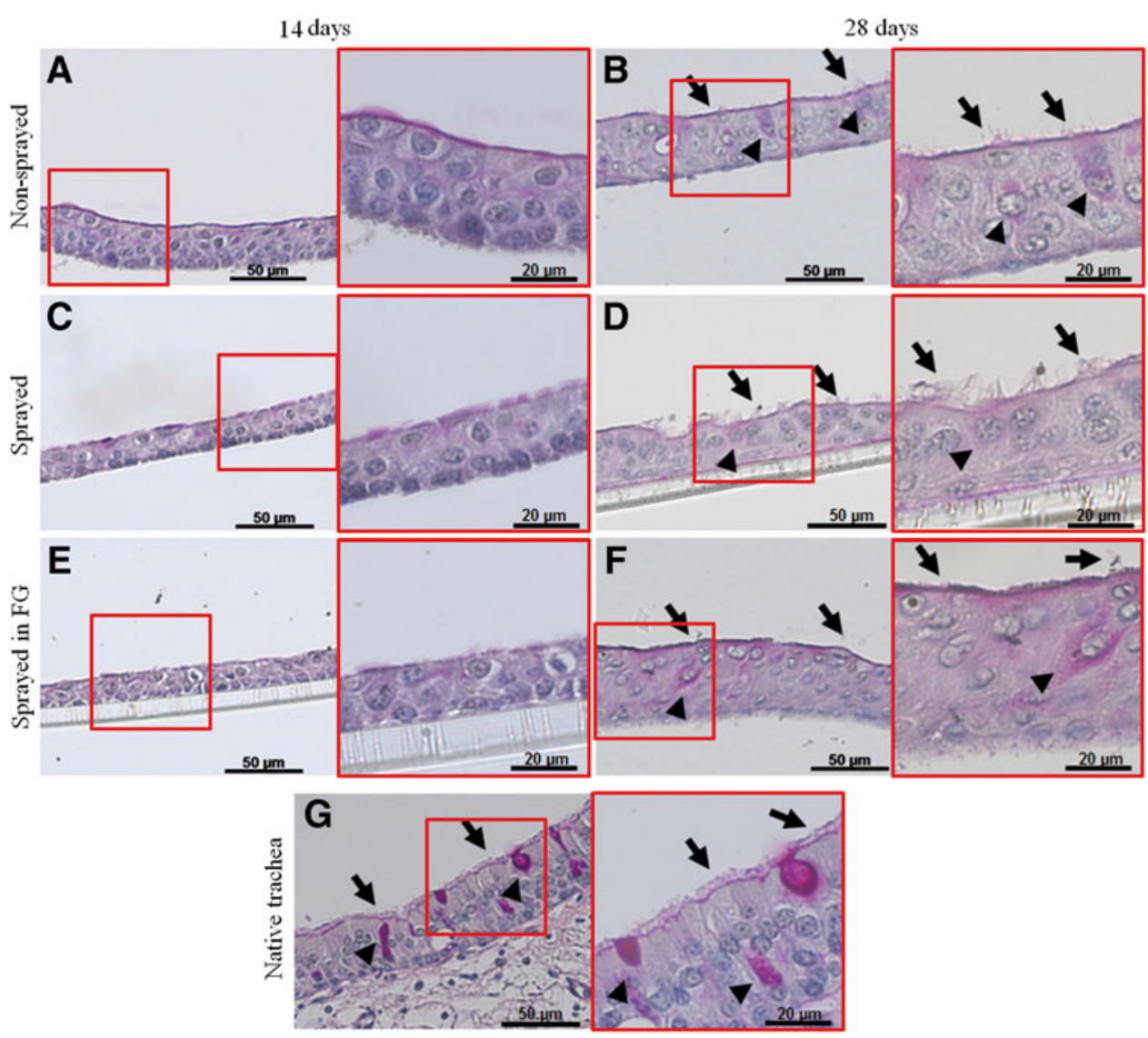

FIG. 5. PAS staining of long-term culture air-liquid interface of RECs after spraying with and without fibrin gel after 14 and 28 days. (A, B) Nonsprayed control, (C, D) sprayed without FG, (E, F) sprayed with fibrin gel, (G) native trachea. After 14 days, RECs build up a layered structure with recognizable basal and apical cells in all assays. After 28 days, cilia are visible on the apical surface (arrows) and goblet cells are formed (arrowheads). In the cells sprayed within fibrin gel, fewer cilia are seen. Air-liquid interface was achieved by culture in insets. Scale bars: $50 \mu \mathrm{m}$ in overview, $20 \mu \mathrm{m}$ in magnification. FG, fibrin gel; PAS, periodic acid Schiff's reaction.

\section{Discussion}

We proposed spray application of ovine vSMCs and RECs for tissue engineering of tubular constructs. As particularly RECs are sensitive and their differentiation in vitro is a challenge, a positive outcome of this study was uncertain. The study of Roberts et al. had shown first promising results for ovine RECs in terms of growth kinetics but not shown results for survival rates or with regard to epithelial differentiation. ${ }^{6}$ Here, we were able to show epithelial differentiation by means of pan-cytokeratin expression and ciliary development of ovine RECs with no evident long-term influence of the spray application.

In the literature, several methods and protocols can be found for spraying of various different cell types.
One important objective for spraying experiments was given by Veazey et al., who proposed to reach fibroblast survival rates of more than $50 \%$ as the goal of their study. ${ }^{4}$ This objective was exceeded by far in our study. To find optimal conditions by means of pressure and velocity, vSMCs were analyzed. We did not see any change in survival rates compared with the control for pressures till 0.8 bar. Similarly, the XTT assay has not shown any significant difference in proliferation. The increased $\mathrm{LDH}$ level for both cell types on day 1 , however, shows that the spraying puts the cells under stress for a very limited time, as it is already normalized on day 3 . Thus, spraying does not have a long-term effect on survival or necrosis and cells do not respond negatively to the applied shear 


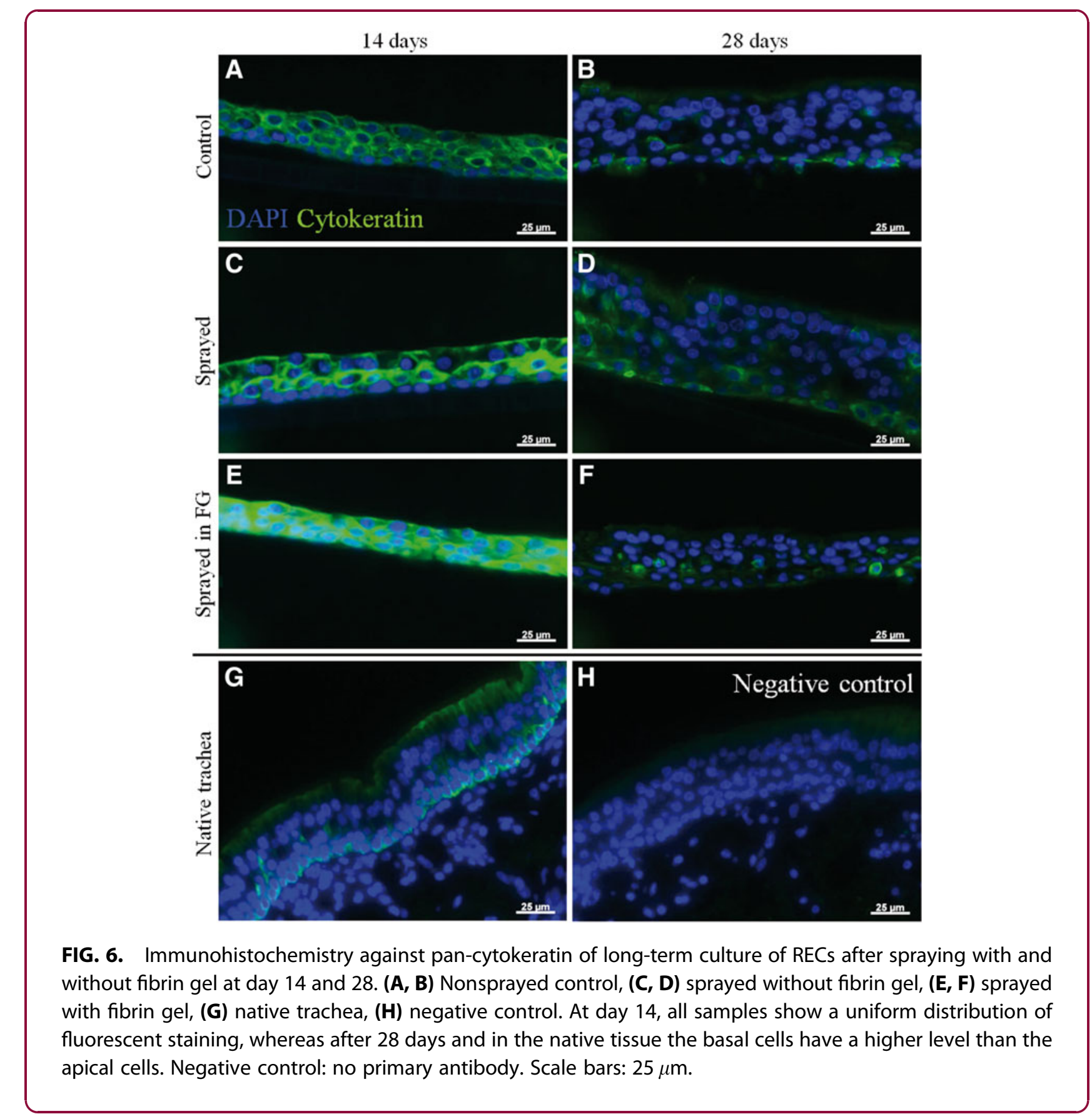

and elongation stresses. Similar results were reported by Schlabe et al. for dermal papilla and dermal sheath cells: The LDH level was higher only within the first medium change, whereas the growth rate was not altered. ${ }^{23}$ Further effects of spraying on the cells were excluded by immunohistochemistry and histology, where the sprayed and nonsprayed cells show comparable results. However, epithelial cells sprayed in a thin layer of fibrin gel show less cilia on their surface. This might be because the fibrin gel slows differentiation of the cells until it is degraded, thus deferring the differentiation by some days, though this was not proved.

Several other groups have assessed the survival rates of cells after spraying with different air pressures with airbrush devices. Spraying with higher pressures can produce a different spray, resulting in finer particles or a more uniform cell layer. Still, this is highly dependent on the spraying device used. With our setup, a 
good spray was already produced with a pressure of 0.4 bar. In general, next to the nozzle dimension, the pressure is a process parameter that is related to the shear the cells may experience during spray formation. Veazey et al. tested air pressures between 0.41 and 1.24 bar and showed a direct dependence of the survival of bovine dermal fibroblasts. ${ }^{4}$ Similarly, Nahmias et al. report survival rates of NIH 3T3 cells of $64 \%$ at a pressure of 0.97 bar till $90 \%$ for a pressure less than 0.34 bar. $^{3}$ Tritz et al. have shown chondrocyte survival rates of $88 \%$ and $80 \%$ in alginate gels 3 days after spraying for pressures of 0.9 and 1.2 bar. $^{2}$ In another study, the same group reports a survival rate of $52 \%$ for human mesenchymal stem cells in the same setup with a pressure of 0.9 bar. $^{24}$ Roberts et al. report a chondrocyte survival of $70-84 \%$ depending on air flow rates between 4 and $8 \mathrm{~L} / \mathrm{min}$ (which corresponds to different air pressures as well). ${ }^{6}$ Thus, higher pressures evoke higher shear and elongation stresses on the cells and reduce their survival. Hence, the unchanged survival of vSMCs and $88.5 \%$ survival rate of our RECs at a pressure of 0.4 bar are very good results.

Duncan et al. propose that survival studies after spraying alone do not suffice to validate the influence of spraying on cells. ${ }^{10}$ We could exclude an effect on cell lysis with normal LDH-levels in the cell culture medium from day 3. Furthermore, we assessed expression of $\alpha$-SMA and pan-cytokeratin for vSMCs and RECs, respectively, after 3-5 days in culture and demonstrated an expression pattern comparable to the control. RECs were also cultured till 28 days and showed enhanced differentiation with goblet cell appearance, columnar shape of the apical cells, and pan-cytokeratin expression comparable to the native control. In both assays without fibrin gel, most cells were ciliated after this period, and cells sprayed with fibrin gel show fewer and less developed cilia probably due to initial fibrin gel degradation.

Thus, spraying is a highly promising procedure for application of RECs. As mentioned earlier, this is of special significance for tissue engineering approaches to develop functional constructs for trachea or bronchi. Experiments in this specific field have not yet been conducted. However, with the approach of embedding the RECs in fibrin gel, one can imagine spray coating even difficult topographies such as tubes. This is of particular interest, as fibrin gel was already proved to be a suitable scaffold for RECs. ${ }^{19}$ In literature, various approaches are reported where fibrin gel is used as a carrier for application of cells. Most of these have shown successful application of keratinocytes onto wounds. ${ }^{7,13,14,25}$ Still, some studies were focused on the development of tissue-engineered constructs: The team of Steinhoff has spray-applied stem cells or stem cell/endothelial cell mixtures in a fibrin glue for coating of heart valve scaffolds and report the desired homogeneous cell distribution. ${ }^{8,26}$ Farhat et al. were already able to demonstrate tissue engineering of porcine urothelium successfully in vivo. ${ }^{15} \mathrm{In}$ addition to better cell adhesion, fibrin supports cell growth by enhanced diffusion of growth factors and by acting as a nutrient. Furthermore, it can be produced autologously and is biodegradable. Thus, spray application of cells in fibrin gel can be seen as a highly viable and promising option for tissue engineering approaches.

In this study, the influence of air pressures and cell suspension velocity on cell survival and differentiation capacity was tested to determine optimal spraying parameters without adverse effects. Apart from a slight reduction of the survival rate in RECs, no evident influence of spraying was found in longer culture periods. However, the embedding of cells in fibrin gel seems to at least slow down the ciliary development.

Spraying of vSMCs and RECs is a highly promising approach for coating of tissue-engineered constructs. When spraying the cells with fibrin gel, unfavorable topographies (as the lumen of tubular constructs) can be coated evenly with a thin cell layer. In future studies, we will assess the luminal coating with cells in detail.

\section{Acknowledgments}

This work was supported by the European Union's Seventh Framework Program (FP7/2007-2013 under grant agreement No. NMP3-SL-2012-280915) and a grant from the START program of the Medical Faculty of RWTH Aachen University. The authors are grateful to the Institute of Laboratory Animal Science of the RWTH Aachen University Hospital headed by Univ.Prof. Dr. med. René H. Tolba, especially Dr. med. vet. Anna Woitok and Mr. Thaddäus Stopinski for their excellent help with the animal material. For technical assistance in the lab, they are grateful to Ms. Irina Appel, Ms. Julia Krapp, and Mr. Kai L. Gessenich.

\section{Author Disclosure Statement}

No competing financial interests exist.

\section{References}

1. Bahoric A, Harrop AR, Clarke HM, et al. Aerosol vehicle for delivery of epidermal cells-an in vitro study. Plast Surg. 1997;5:153-156.

2. Tritz J, Rahouadj $\mathrm{R}$, de Isla N, et al. Designing a three-dimensional alginate hydrogel by spraying method for cartilage tissue engineering. Soft Matter. 2010;6:5165-5174. 
3. Nahmias $Y$, Arneja A, Tower $\pi$, et al. Cell patterning on biological gels via cell spraying through a mask. Tissue Eng. 2005;11:701-708.

4. Veazey WS, Anusavice KJ, Moore K. Mammalian cell delivery via aerosol deposition. J Biomed Mater Res B Appl Biomater. 2005;72:334-338.

5. Goedkoop R, Juliet R, You PH, et al. Wound stimulation by growth-arrested human keratinocytes and fibroblasts: Hp802-247, a new-generation allogeneic tissue engineering product. Dermatology. 2010;220:114-120.

6. Roberts A, Wyslouzil BE, Bonassar L. Aerosol delivery of mammalian cells for tissue engineering. Biotechnol Bioeng. 2005;91:801-807.

7. Cohen M, Bahoric A, Clarke HM. Aerosolization of epidermal cells with fibrin glue for the epithelialization of porcine wounds with unfavorable topography. Plast. Reconstr. Surg. 2001;107:1208-1215.

8. Kaminski A, Klopsch C, Mark P, et al. Autologous valve replacementcd133+ stem cell-plus-fibrin composite-based sprayed cell seeding for intraoperative heart valve tissue engineering. Tissue Eng Part C Methods. 2011;17:299-309.

9. Zimmerlin L, Rubin JP, Pfeifer ME, et al. Human adipose stromal vascular cell delivery in a fibrin spray. Cytotherapy. 2013;15:102-108.

10. Duncan CO, Shelton RM, Navsaria $H$, et al. In vitro transfer of keratinocytes: comparison of transfer from fibrin membrane and delivery by aerosol spray. J Biomed Mater Res B Appl Biomater. 2005;73:221-228.

11. Fraulin FO, Bahoric A, Harrop AR, et al. Autotransplantation of epithelial cells in the pig via an aerosol vehicle. J Burn Care Rehabil. 1998;19:337345.

12. Hafez AT, Afshar K, BäGli DJ, et al. Aerosol transfer of bladder urothelial and smooth muscle cells onto demucosalized colonic segments for porcine bladder augmentation in vivo: a 6-week experimental study. J Urol. 2005;174:1663-1668.

13. Falanga V, Iwamoto $S$, Chartier M, et al. Autologous bone marrow-derived cultured mesenchymal stem cells delivered in a fibrin spray accelerate healing in murine and human cutaneous wounds. Tissue Eng. 2007;13:1299-1312.

14. Grant I, Warwick K, Marshall J, et al. The co-application of sprayed cultured autologous keratinocytes and autologous fibrin sealant in a porcine wound model. Br J Plast Surg. 2002;55:219-227.

15. Farhat WA, Chen J, Sherman C, et al. Impact of fibrin glue and urinary bladder cell spraying on the in-vivo acellular matrix cellularization: a porcine pilot study. Can J Urol. 2006;13:3000-3008.

16. Janmey PA, Winer JP, and Weisel JW. Fibrin gels and their clinical and bioengineering applications. J R Soc Interface. 2009;6:1-10.

17. Jockenhoevel S, Zund G, Hoerstrup SP, et al. Fibrin gel—advantages of a new scaffold in cardiovascular tissue engineering. Eur J Cardiothorac Surg. 2001;19:424-430.

18. Weinandy $S$, Rongen $L$, Schreiber $F$, et al. The biostent: novel concept for a viable stent structure. Tissue Eng Part A. 2012;18:1818-1826.

19. Cornelissen CG, Dietrich M, Kruger S, et al. Fibrin gel as alternative scaffold for respiratory tissue engineering. Ann Biomed Eng. 2012;40:679-687.

20. Tschoeke B, Flanagan TC, Koch S, et al. Tissue-engineered small-caliber vascular graft based on a novel biodegradable composite fibrin-polylactide scaffold. Tissue Eng Part A. 2009;15:1909-1918.

21. Yamaya M, Finkbeiner WE, Chun SY, et al. Differentiated structure and function of cultures from human tracheal epithelium. Am J Physiol. 1992;262:L713-L724.

22. Flanagan TC, Cornelissen C, Koch S, et al. The in vitro development of autologous fibrin-based tissue-engineered heart valves through optimised dynamic conditioning. Biomaterials. 2007;28:3388-3397.

23. Schlabe J, Johnen $C$, Schwartlander R, et al. Isolation and culture of different epidermal and dermal cell types from human scalp suitable for the development of a therapeutical cell spray. Burns. 2008;34:376-384.

24. Tritz-Schiavi J, Charif N, Henrionnet C, et al. Original approach for cartilage tissue engineering with mesenchymal stem cells. Biomed Mater Eng. 2010;20:167-174.

25. Kirsner RS, Marston WA, Snyder RJ, et al. Spray-applied cell therapy with human allogeneic fibroblasts and keratinocytes for the treatment of chronic venous leg ulcers: a phase 2, multicentre, double-blind, randomised, placebo-controlled trial. Lancet. 2012;380:977-985.

26. Klopsch C, Gabel R, Kaminski A, et al. Spray- and laser-assisted biomaterial processing for fast and efficient autologous cell-plus-matrix tissue engineering. J Tissue Eng Regen Med. 2012; DOI: 10.1002/term.1657.
Cite this article as: Thiebes AL, Albers S, Klopsch C, Jockenhoevel S, Cornelissen CG (2015) Spraying respiratory epithelial cells to coat tissue engineered constructs. BioResearch Open Access 4:1, 278-287, DOI: 10.1089/biores.2015.0015.

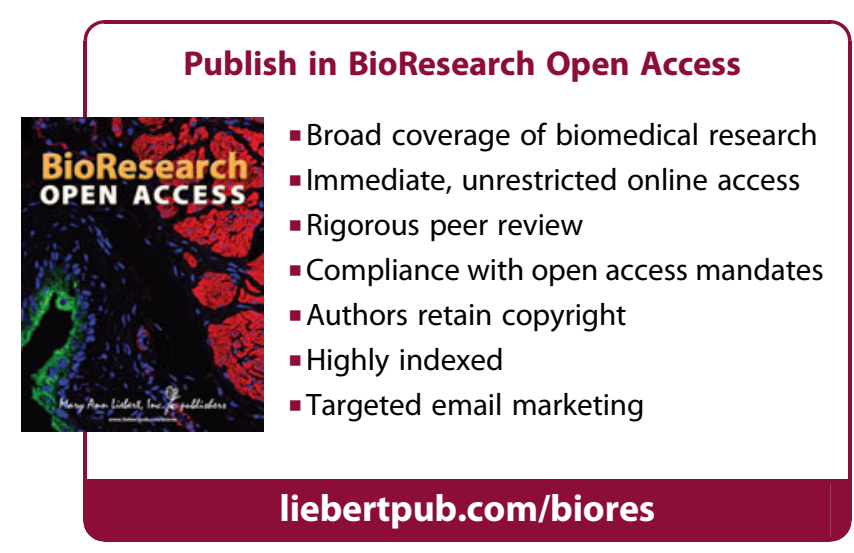

